\title{
EL TEATRO DE MAITE AGIRRE: LA FIESTA DE CONFABULACIÓN CON EL PÚBLICO
}

\author{
MAITE AGIRRE THEATRE: \\ THE FESTIVAL OF COMPLICITY WITH THE PUBLIC \\ Miguel Ángel MURO MUNILLA \\ Universidad de La Rioja \\ miguel-angel.muro@unirioja.es
}

Resumen: En este artículo pretendo una aproximación a la obra teatral de Maite Agirre, obra que se caracteriza por estar concebida como una fiesta en la que el público está convocado a participar de forma cómplice, con propuestas vitalistas que indagan en el lenguaje teatral e invitan a no renunciar a los ideales, a los deseos de vivir una vida más plena y auténtica que la impuesta por una visión acomodada.

\begin{abstract}
In this article I try an approach to the theater written by Maite Agirre, a work that is characterized by being conceived as a festival in which the public is called to participate with complicity, with vitals proposals that explore theatrical language and invite you not to give up the ideals and desires to live a fuller and more authentic than that imposed by a accommodated vision.
\end{abstract}

Palabras clave: Maite Agirre. Teatro. Fiesta. Confabulación. Público. 
Key words: Maite Agirre. Theater. Festival. Complicity. Public.

A Maite Agirre, por su generosidad y su afecto

\section{TRAYECTORIA PROFESIONAL DE MAITE AGIRRE}

Maite Agirre (Zarautz, 1955), autora, actriz y directora de teatro, comienza su formación en el grupo Dagoll-Dagom, en 1973, en el momento en que ésta y otras formaciones (Els Comediants, Els Joglars, La Fura dels Baus, La Cubana, Tricicle, Vol-Ras o La Cuadra de Sevilla) remueven el panorama teatral español con propuestas experimentales que ganan el favor de un público hastiado del teatro convencional, con espectáculos donde la palabra cede gran parte de su presencia e importancia a los elementos espectaculares (cuerpo del actor, música...), el lugar teatral se reacomoda a una concepción más global y participativa del espectáculo, tendiendo a difuminar la separación escenario/patio de butacas, o buscando otros espacios alternativos (la calle, polideportivos o estadios...), y reclamando la participación del espectador. Tras su paso por la Escuela de teatro de Sans y su trabajo con Lluís Pascual, Mario Gas o Jordi Graells y una etapa en la compañía italiana Domus de Janas, Maite Agirre vuelve a Euskadi en 1985 y funda la compañía Agerre Teatroa (Teatro en un claro del bosque), que pone en escena una serie de obras caracterizadas por alejarse del teatro convencional y comercial: Woyzeck de G.Büchner, Beckett I y Beckett II, sobre textos de Samuel Beckett y Pelotari, creación colectiva con la colaboración del escultor Jorge Oteiza. En 1991 realiza el espectáculo Pantzart sobre la pastoral carnavalesca zuberotarra ${ }^{1}$ que, a juicio de la propia autora, supone un antes y un después en la historia y el trayecto de Agerre Teatroa, ya que es el inicio de su inmersión en el teatro popular y en el carnaval, en la que se insertarán luego La Celestina y Don Quijote. De 1992 es Molly Bloom, monólogo sobre el último capítulo del Ulises de Joyce, muy bien recibido por público y crítica. En

${ }^{1}$ Se trata de una muestra de teatro popular de la provincia de Soul o Zuberoa y pertenece al subgénero de la Pastoral (otros subgéneros de este teatro son la Maskarada, los Astolasterrak y las llamadas Ihauteetako trajikomediak (tragicomedias de carnaval). La obra es anónima y fue representada por Jakes Ohienarte y traducida al bearnés por Cazaurang en 1.802. Maite Agirre presentaba así la obra: «Además de Pantzart, ese gran comilón y violador de mujeres casadas, así como de su mujer Pantzartina, tan sensual y libertina como él, tenemos a Bakus y a su mujer Poloni, «más borrachos que el vino». Durante la agonía de Bakus (pues le han mezclado agua en el vino) aparecerán MEDEZIA, BARBERA y POTIKARIA. Son «el saber» (el «saber» como «poder» que diría Foucault) y, naturalmente, el pueblo aprovecha la ocasión para burlarse de ellos haciéndolos aparecer como auténticos feriantes.» («Y del frontón de pelota nos vamos de hoz y coz al teatro popular: Pantzart»). 
1994, en la misma línea, adapta para la escena e interpreta el texto de Arantxa Urretabizkaia Zergatik panpox?, el monólogo de una mujer en un día cualquiera donde se va manifestando la situación en que se encuentra su vida, su relación con su hijo, consigo misma y con la gente. En 1997 escribe $Y$ María, tres veces amapola, María... (Pasión y exilio de María de la O Lejárraga), sobre esta interesante mujer que escribió para su marido, Martínez Sierra, tras el que desapareció en esta faceta, pero que fue también diputada en la segunda República y activista femenina; la obra se estrena en El Canto de la Cabra (Madrid), en enero de 1998. En el 2000 adapta e interpreta $M a$ rranadas de la escritora bayonesa Marie Darrieussecq, papel que le vale el premio a la mejor actriz del festival de teatro de Medina de Pomar.

Paralela a esta actividad, Maite Agirre participa en diferentes talleres de investigación teatral ${ }^{2}$. En el encuentro «Arnasa» de 2002 presenta Ubu Rey de Alfred Jarry. Este mismo año publica Y María, tres veces amapola, María y Bilbao, Lauaxeta, tiros y besos. En 2004 estrena ;Puta vieja alcahueta Celestina!, una lectura personal del mito. En 2005 estrena Chicas bonitas, alegres maizales (Neska politak, artasoro alaiak), versión de su obra La baladilla de San Sebastián (Max de teatro 2007 al mejor texto en euskera). Cabaret infantil (Haur Kabareta) recibe también el Max a mejor texto en euskera en 2008. A continuación escribe Ramón y Ramona (cuya versión, titulada Secando Charcos, Putzuak Lehortzen conseguirá de nuevo el Max a mejor texto en euskera del 2010). En agosto de 2009 pone en escena Dulcineia e o Cavaleiro dos Leões, otra lectura personal de la autora de un mito universal, el Quijote, que realiza en Maputo, Mozambique, con el grupo Luarte en el teatro Avenida, que dirige Henning Mankell y que presentará en Errentería con el título Doltza, Dulcinea Quijote versus Teresa Panza, con una versión infantil titulada ¿Quién ha visto a Dulcinea? (Nork ikusi du Dultzinea?).

\section{POÉTICA DE LA AUTORA}

La propuesta de Maite Agirre como autora está en concordancia con su formación, su concepción del teatro (y de la vida) y su práctica teatral. Es la propuesta de una apasionada por el teatro, entendido como forma de indagación en el vivir y de relación con los demás. Agirre pretende proponer al público otra visión del mundo y de la vida distinta a la «oficial», a la que ha impuesto el hábito burgués como «natural» o única posible y que es clara-

\footnotetext{
${ }^{2}$ Remito a http://www.euskomedia.org/aunamendi/21056.
} 
mente insatisfactoria y deficiente. Su teatro, de ese modo, se convierte en un lugar para la participación y la reflexión que apunta sustancialmente a la for$\mathrm{ma}^{3}$. Agirre, que se define a sí misma como «una mujer que se relaciona con los demás a través del teatro», manifiesta también que le «gusta profundizar en los retos, sin pasar por ellos como el vuelo de una mariposa.» ${ }^{4}$ Su poética es la del taller o el laboratorio teatral: preguntas, investigación, exploración, inquietud, riesgo; una actitud contraria al inmovilismo, basada en las tentativas, en el ensayo. El teatro es visto por Agirre, en este sentido, como lugar de encuentro de propuestas diversas, diferentes, incluso opuestas, que pueden dialogar y enriquecerse con ese diálogo, que pueden incluso llegar a armonizarse. Destaca en buena parte de su teatro la propuesta lúdica desde el que se piensa y desarrolla, tan radical que deja los espectáculos abiertos a la reescritura, al cambio, a la adaptación a un determinado público y a un lugar determinado, a la colaboración y al mestizaje con grupos de otros lugares (Mozambique, Chile, Méjico...).

El teatro es concebido por Agirre como un espacio y un tiempo mágicos, un paréntesis subversivo en la sujeción del ser humano a la servidumbre de la realidad fáctica donde es ineludible el respeto y sometimiento a sus condiciones y al orden establecido. Por ello, la libertad (un claro impulso de libertad), impregna el hecho teatral de Agirre, permitiendo, entre otras cosas sustanciales, la ruptura constante de la «cuarta pared», la inclusión del público en el devenir de la acción y la carnavalización de buena parte de sus propuestas.

\subsection{Carnavalización atenuada}

Hay, en efecto, algunos aspectos sustanciales del teatro de Agirre que pueden ser entendidos y explicados a partir de la categoría antropológica y

\footnotetext{
${ }^{3}$ Como decía la autora en una entrevista: «La modernidad tiene que estar en el lenguaje, no tanto en las historias, ;pero si siempre hablamos de lo mismo, de amor, muerte y sexo!» («Secando charcos. Una obra sobre el amor»).

http://www.euskalnet.net/agerreteatroa/webpage/obras/charcos/galeria/secando_charcos.pdf.

${ }_{4}^{4}$ «Me detengo — sigue diciendo-, escucho lo que me dice el proyecto, los personajes, y me pongo a buscar respuestas. Cuando nos encontramos con el escultor Jorge Oteiza e iniciamos uno de nuestros primeros mestizajes y el espacio metafísico de su escultura comprendí que había que pararse, detenerse, escuchar, mirar, y de esta experiencia surgió una tetralogía, es decir cuatro momentos diferentes, cuatro espectáculos, cuatro años de trabajo. También ha sucedido con Celestina, ahora con D. Quijote. Me gusta detenerme el tiempo que haga falta y plantearme todas las preguntas posibles y escuchar cómo estos proyectos son cosas vivas que continuamente te retan, te desafían y, cómo no, te seducen.» (««El gran milagro del teatro», entrevista con la actriz, dramaturga y directora artística Maite Agirre», Kutsenba cartão, en http://kutsemba.wordpress.com/).
} 
estética de la Fiesta, la carnavalización o del grotesco festivo, ya que buena parte de sus obras tienen un claro y atractivo componente carnavalesco aunque haya en ellos una cierta - y esperable, por la fecha- contención, un autocontrol y una orientación «didáctica», «constructiva» que frena la desmesura vitalista y el estallido que pondría el mundo patas arriba (por utilizar una expresión muy gráfica, que representaría muy bien la condición propia de la Fiesta) y llevaría al caos.

Hay que tener en cuenta que ya el drama satírico o las farsas mostraban dos fuerzas actuantes contrarias, opuestas: la que apunta hacia el caos, la disolución de cualquier orden, y la que apunta al orden contrario al establecido, que es la que viene a predominar, dejando establecido un orden determinado. Como expuso Caro Baroja, el carnaval es «una reglamentación del desorden tan reglamentada como el orden mismo» (1985: 205). El hecho de que el participante en la Fiesta y en el Carnaval tenga conciencia de que se halla en un paréntesis, vuelve compleja la naturaleza del hecho y cuestiona su condición liberadora y lo convierte más en válvula de escape transitoria que en aspiración a un cambio radical y permanente, más o menos respetuoso del orden o afecto al desorden y la anarquía.

Notan Julio Caro Baroja y Emilio Temprano que «las fiestas populares también se marchitan» y que el Carnaval actual no pasa de ser un recordatorio de fiestas paganas o de paréntesis en la sujeción a las imposiciones del cristianismo (1985: 293). Lo interesante es ver cómo, domesticada la fuerza de la Fiesta y del Carnaval, el teatro se convierte en un reducto donde todavía late el espíritu primigenio, no con esa condición de recuerdo, sino como fuerza actuante, aunque a estas alturas de civilización y burguesía lo haga de forma amortiguada, canalizada, reglamentada por la comedia.

En este sentido, Agirre concibe el teatro y el lugar teatral en varias de sus obras a modo de una gran plaza pública con la rotura de la «cuarta pared» y la inclusión del público en el hecho teatral como si fuera una fiesta, conversión que se produce porque, previamente, se ha entendido el teatro como algo que se ha de dar en el ámbito de la sociabilidad popular y de la fiesta desinhibidora y, en la medida de lo posible, transgresora.

En el teatro de Maite Agirre hay, sobre todo, exaltación de la vida y de su fuerza generadora, fuera de trabas, diques o contenciones, un vitalismo que supone la afirmación de la vida por encima de todas las dificultades y trabas y sinsabores; afirmación de la vida múltiple y variada, optimismo. El teatro, el hecho teatral se concibe y desarrolla por parte de la autora a modo de fiesta que sirve o ayuda a regenerar al espectador y la propia vida, como remi- 
niscencia de la Fiesta o del Carnaval; el teatro es, por tanto, un hecho colectivo y celebrativo. Esto no quiere decir que nos hallemos ante un mundo ingenuamente feliz. En él aparecen también las vetas dolorosas y siniestras (no se ha de olvidar que la esencia de lo grotesco es tragicómica; García Pascual, 2006: 31): el vitalismo de la Fiesta y del Carnaval conllevan la exaltación de la vida aun a costa de vidas particulares, la exaltación del impulso vital que puede conllevar en su satisfacción la sujeción, el dolor y hasta la aniquilación de otros seres: como ocurre con María Lejárraga, con Celestina, con Don Quijote, con Ramona...

No llega a haber grandes desmesuras en este teatro, ni se coloca el mundo al revés (con la degradación de los valores instituidos y la sustitución por sus contrarios o por la ausencia de cualquier valor), pero sí están presentes el pensamiento dominante y su contestación (en el dialogismo a que se refiere Bajtín). La Fiesta que propone Agirre no llega a ser orgiástica ni propugna la liberación absoluta y feroz de todos los instintos (comida, bebida, sexo) ${ }^{5}$, pero sí anima a entrar de lleno en la celebración y gozar de lo bueno de la vida, y se muestra desinhibida al nombrar lo escatológico o al producirlo en escena (las pedorretas de Sancho o la sexualización de Ramón y Ramona, por ejemplo).

Esta libertad se reclama también respecto a cualquier jerarquía establecida, al poder político y cultural ${ }^{6}$, porque la Fiesta o el Carnaval son microcosmos fundamentalmente populares que gozan con la degradación de la autoridad que los oprime. Sin embargo, el teatro de Maite Agirre no induce a la subversión política, ni da cabida a la injuria o a la sátira corrosiva, ni tampoco entra en asuntos religiosos. Tiene más que ver, en este sentido, con el «conjunto alegre y bienhechor» de que habla Bajtín (1987: 23).

No parece casual, en este sentido, que la mayor parte de las obras que jalonan la carrera teatral de Maite Agirre y de Agerre teatroa tengan una clara condición de marginalidad y que arrojen una mirada desestabilizadora sobre un determinado orden y estado de cosas caracterizado por una presunta racionalidad y sensatez propias de una concepción de la vida burguesa, contraria al juego, al sueño. También es comprensible, desde este punto de vista, que dos de las elecciones más sonadas de la autora para versionar sean $L a$ Celestina y el Quijote, dos muestras señeras de la cultura popular, ejemplificación adecuada de la noción de cultura carnavalesca de Bajtín.

\footnotetext{
${ }^{5}$ Y mucho menos anima a la violencia o a la eliminación de vínculos familiares y sociales.

${ }^{6}$ Pero no a los lazos familiares.
} 
Hay en estas obras también metamorfosis en el paso de lo humano al títere y viceversa (en Cabaret infantil o en los Quijotes, por ejemplo), que, en su deshumanización, contribuyen a la remoción de los puntales del orden establecido y a la entrada de lo grotesco siniestro; hay mezcla, confusión, eclecticismo... de valores y de gentes; hay bufones, payasos y locos (el más grande: don Quijote); hay máscaras que aportan el ocultamiento, por un lado, pero también la encarnación de fuerzas actuantes en los ritos. Hay música constantemente (de txalaparta, con frecuencia, con sus resonancias folklóricas telúricas), que invita al baile a la participación en la fiesta.

\section{LAS OBRAS DE MAITE AGIRRE A LA LUZ DE UN ENFOQUE CARNAVALESCO}

\subsection{Y María, tres veces amapola, María...}

Maite Agirre aborda en esta obra la llamativa e importante figura de la maestra, escritora, activista femenina y diputada socialista María de la $\mathrm{O}$ Lejárraga, esposa y colaboradora oculta del dramaturgo Gregorio Martínez Sierra, para quien escribió incluso después de que la abandonara por la actriz Catalina Bárcena. «Una olvidada de sí misma», considera Agirre que fue María Lejárraga, en este sentido, si bien en lo social y lo político se manifestó a plena luz y a cara descubierta en un tiempo «en el que todo estaba por hacer» (Agirre, 2002: 8) en cuanto a la solidaridad y derechos sociales de las mujeres y los desvalidos.

La información sobre María Lejárraga, e incluso parte de los textos que Agirre pone en boca de su protagonista, vienen de los diarios Una mujer por los caminos de España y Gregorio y yo y de algunas de las obras de teatro de ambos, de la obra María Lejárraga, una mujer en la sombra escrita por Antonina Rodrigo, de algunas cartas de Gregorio y de poemas de Juan Ramón Jiménez. La propuesta teatral de Agirre parece tener como cometido poner en pie una estructura, una especie de teatrillo que permita recuperar la propia voz de la mujer ${ }^{7}$, de su entorno y de su tiempo.

Agirre compone su obra en torno a una María Lejárraga visitada por sus fantasmas más dolorosos («Me dispongo a sostener la guerra contra el sufrimiento que sin querer evocará mi mente», Agirre, 2002: 14), desde la

\footnotetext{
${ }^{7}$ Nieva de la Paz (1999) pormenoriza con detalle la procedencia de algunos parlamentos de la obra.
} 
derrota y el fracaso en su vida afectiva y en sus ideales sociales: abandonada por Gregorio (para quien, sin embargo, siguió escribiendo) y en la soledad del exilio, tras el triunfo de los sublevados contra el gobierno legítimo de la República. Sólo la figura de Juan Ramón Jiménez (amigo de María y autor del verso que da título a la obra) atenúa en algo la soledad y la amargura, aunque su presencia convoque también el dolor de la nostalgia.

Lo que podría considerarse la primera parte de la obra gira en torno al amor y la maternidad y la autoría (y las relaciones unamunianas o pirandelescas entre el autor y sus criaturas). Serán aquí unos personajes (el «titiritero y la joven» picasianos, incluso un títere) quienes den cuerpo y voz a los recuerdos ( «Seas un personaje o seas mi corazón el que me habla, haz el favor de callarte», Agirre, 2002: 15). A ellos se suma la voz del Poeta, que, sobre todo, exhorta a María a asirse a su amor y no dejar que se le escape. También Gregorio se corporeizará en las tablas respondiendo a los recuerdos cariñosos de María con la petición machacona de que le escriba más obras.

Sobre este tema viene a añadirse, con intención de ahogar al primero, el de la actividad social y política de María, introducido por una canción republicana y sustanciado en un telegrama que le entrega el Poeta en el que las Organizaciones de Granada la proponen como candidata a Diputada por la República; este tema es desarrollado después con recuerdos de mítines y contacto con la gente pobre, hasta la llegada de la noticia de la muerte de García Lorca, la derrota de la República y el exilio. La tercera parte, señoreada por la soledad y la muerte, presenta la de Gregorio y el balance desolado que María hace de su vida que viene a culminar la confesión que a lo largo de la obra ha ido haciéndose sobre los rasgos de su carácter y las causas de su fracaso: la cobardía o la falta de orgullo para reclamar la posesión de algo, la generosidad en dar a Gregorio todo su amor y las obras que escribe(n) como si fueran hijos a los que bastara el nombre del padre, el compromiso con los trabajadores y las mujeres del pueblo desarbolado por la victoria fascista, su anulación a favor del hombre: «iSentí mi derecho como un pecado. Mi inteligencia como un crimen! Puse toda mi fuerza a tus pies y en vez de gritar ¡quiero vivir!, neciamente me dije: quiero ayudar al hombre. A fuerza de siglos de esclavitud hemos llegado a tener alma de esclavas» (Agirre, 2002: 32). Pero el final se abre a la serenidad e incluso a la alegría. Después de que María proponga «Vámonos, en silencio..., despacio..., serenamente, ahora que, una vez más vuelve la primavera», la coda queda a cargo de personajes simbólicos (la Joven y el Titiritero, de nuevo, y un Olivo, la Rama, la Fuente, El Viento, la Flor Adelfa, una Rosa Pálida, un Lirio de Agua, un Jazmín) en un ambiente de fiesta popular, con su música y un espectáculo de mario- 
netas, donde el Viento proclama la importancia de la voluntad, barre la tristeza de la melancolía y proclama la pujanza de la vida, a la que todos - espectadores incluidos- somos invitados.

Cuida Agirre con esmero los componentes técnicos de su obra: música, iluminación y decorados, llevándola unas veces a las cercanías del teatro simbolista y otras a la vanguardia, y extrayendo de ellos parte de la significación de la obra. Así sucede con la romanza de Lina «Me dices que ya no me quieres» de la zarzuela Las golondrinas, de José María Usandizaga, con libreto de Martínez Sierra/ Lejárraga, a partir de su obra Saltimbanquis, explicita el abandono de Gregorio; o con el «Amor brujo» de Falla recorre la obra como un leit-motiv y es comentado por María en un momento de profunda tristeza: «Mi don Manué, su música aún me suena no ya en los oídos, sino en toda la carne y en toda la sangre... cómo duele la carne dolorida (Vuelve la música de Manuel de Falla)... música cruel y dulcísima, áspera y soñadora, desolada, desgarrada, hecha con sol y llanto... como el amor, oliendo a incienso, sabiendo a fatalidad» (Agirre, 2002: 24); también con la suave iluminación que acompaña la entrada de María en escena o el oscuro que se hace en un momento cuando la protagonista cierra los ojos; $o$, en fin, con los menhires que tornan extraño, irreal el escenario y que van cambiando de posición creando distintos ambientes. Atiende también la autora a la fluidez y agilidad del desarrollo de la trama, con una estructuración por escenas de las que salen o ingresan personajes como quien aparece o desaparece de la oscuridad a la luz.

Ya en esta obra Agirre rompe la «cuarta pared», distanciando al espectador en un momento dado, e involucrándolo al mismo tiempo en el juego del teatro («El PoETA: (Levantándose y dirigiéndose hacia los espectadores) Pero aquí todos somos actores, y sólo actores, y el teatro es la ciudad. ¡Me voy! (Se dirige hacia el patio de butacas.) (Agirre, 2002: 19).

Hay también otro recurso mediante el cual Agirre amplía las condiciones espaciales y temporales de su obra e incorpora al público en el hecho teatral. En un momento dado de la parte dedicada a la actividad política de la protagonista, la acotación dispone que «María mirando hacia el público y sentándose en su butacón rojo crea dos planos espacio-temporales distintos y superpuestos» (Agirre, 2002: 27): el público se convertirá en los asistentes a un mitin, mientras que en el escenario la protagonista mantendrá un diálogo con una joven y un hombre pobres, que quedan «congelados» cuando María abandona su plano.

La tensión que se va acumulando por el recuerdo dolorido de la miseria de las gentes encuentra su manifestación plástica más adecuada en la obra 
mediante la aparición de los titiriteros, de los que la autora puntualiza su «aspecto grotesco» (Agirre, 2002: 29). Para el momento en que el Poeta anuncia consternado el rumor del asesinato de García Lorca, Agirre dispone una composición velazqueña de la escena, «tipo las Meninas», con los personajes «arrodillados como enanos». El final de la parte dedicada a la República está pensado para producir emoción en un público que no puede dejar de sentirse concernido (y conmovido): «(Empieza a oírse una balada revolucionaria y los actores van saliendo lentamente y miran hacia el público. Público y actores se miran mientras escuchamos la balada. Los actores se despiden. Van camino del exilio. María se ha quedado sola)» (Agirre, 2002: 31). Del mismo modo, el final de la obra incorpora al público en la acción ficcional y en la invitación a la fiesta regeneradora ${ }^{8}$ : «La música se reanuda con su ritmo de fiesta. Los titiriteros hacen gestos para entrar a ver su espectáculo. Los espectadores del escenario lanzan monedas a los titiriteros al tiempo que tímidamente se adentran dentro del dolmen a ver el espectáculo al que son invitados./ ¡Vamos, todos a la fiesta, vamos a ver el espectáculo, vamos, pasen y vean! / Los titiriteros también desaparecen tras ellos. Se va haciendo oscuridad. Oímos la música de fiesta. FIN» (Agirre, 2002: 37).

\subsection{BILBAO. Lauaxeta, tiros y besos}

En su segunda propuesta teatral Maite Agirre prescinde de textos ajenos y crea una historia original y propia. Vuelve a ser, no obstante, la plasmación de un ejercicio de memoria, individual e histórica, ambientada ahora en el Bilbao sitiado de la Guerra Civil de 1936, mediante la cual los personajes principales, Mertxe y Leire, hermanas, recuperan su pasado próximo en un intento de revivirlo, entenderlo y aceptarlo o asumirlo.

No creo que esta actividad de la memoria sea tanto - como quieren Leonard y Gabriele, 2008 - un ejercicio de postmodernidad, cuanto algo más intemporal y cercano, más vital: entender un tiempo y unas vidas en los que confluyeron los besos y los tiros: la vitalidad, la amistad, el amor, los sueños de unos jóvenes interferidos por la violencia de la guerra civil española, por las ideas distintas ante el conflicto, por la muerte.

${ }^{8}$ Sobre la que el serio Olivo hace una graciosa y jugosa reflexión: «No he comprendido nunca las fiestas populares y su regocijo colectivo, pero qué alboroto están armando... Eso de alegrarse todo el mundo a un tiempo sin motivo ninguno individual de alegría, sólo porque ha llegado el día señalado para estar alegres, es un verdadero misterio para mí» (2002: 35). 
Técnicamente, Agirre vuelve a propuestas alejadas del realismo escénico. La más llamativa - y básica porque sirve para estructurar la obra — es la de hacer coexistir en el escenario los dos tiempos, siendo el pasado contemplado desde el presente (como ocurre en nuestra memoria), y siendo el paso de uno a otro plano constante. Mertxe y Leire adultas ${ }^{9}$ vuelven al bar de Ángel para revivir diversos días de su juventud, en los que los preparativos de la fiesta o el mero diálogo entre ellos trataban de hacer olvidar los disparos cercanos, la violencia y la muerte (rasgo propio del grotesco), mientras dos amigos, el propio Ángel y Luis rivalizan por el amor de Leire, y se reprochan el uno al otro su belicismo, su patriotismo, su conservadurismo nacionalista (Luis a Ángel) o su pacifismo, su sindicalismo utópico (Ángel a Luis). Leire - invocando el amor libre - se declarará enamorada de los dos, incapaz de elegir entre ambos, a pesar de estar embarazada de Ángel: la vehemencia muy masculina de éste se equilibra en este conflicto con la ternura de Luis. En el debate sobre la libertad y los riesgos del amor y de las responsabilidades contraídas es donde aparecen Lauaxeta y la Asociación Libre de Ensayos Artísticos y el montaje que hicieron en Bilbao de Bodas de sangre. El asesinato de Lorca vuelve a ser mencionado en esta obra y, también - como ocurría en María - la muerte se va adueñando de la escena: Leire muere con su niño al dar a luz, los fascistas penetran en Bilbao y Ángel y Luis mueren en la defensa de la ciudad.

La música vuelve a impregnar la trama y a cargarse de significado. Se trata ahora de una música festiva, con distintas modulaciones. Atenuada, «tocada en tono menor» y con acordeón, para provocar un aire nostálgico en el comienzo; es «toda una fiesta», cuando los jóvenes derrochan vitalidad; suena «como un comentario irónico de la situación», mezclada con las bombas que caen sobre Bilbao, en otro, y al final invade el escenario y se adueña de él, tapando el estruendo de la pelea lúdica entre los dos amigos, que mantienen su cariño, su rivalidad y sus diferencias más allá de la muerte, después de haberse preguntado - en una atractiva concesión al grotesco- por su condición de vivos o muertos. Pero en Bilbao no triunfa la vida, como en María. Como dice Mertxe, «la vida es esta marea que avanza tragándose nuestras pequeñas conquistas e ilusiones», algo, por tanto y como se ha podido ver, muy parecido a la muerte, a la que se aliará el olvido, en forma de excavadora que arrasa el bar dejando el escenario totalmente vacío para el final.

\footnotetext{
${ }^{9}$ Luego sabremos que sólo Mertxe sobrevivió a aquellos días.
} 


\section{3. ¡Puta vieja alcahueta Celestina!}

La semilla de Pantzart germina en el interés de Agirre por textos vitalistas carnavalescos, como La Celestina o el Quijote. Volviendo de entre los muertos, como un nuevo Dante ${ }^{10}$, guiada esta vez no por Virgilio, sino por el vitalista Juan Ruiz, Arcipreste de Hita, presenta Agirre a la protagonista de esta su tercera obra, que revisita el mito de la alcahueta inmortalizado por Fernando de Rojas, con añadidos del Libro de Buen Amor y de la Segunda Celestina de Feliciano de Silva, de quienes toma argumento, parte de la historia y algún fragmento textual que da al habla de Celestina sabor de época y el espesor de la visión del mundo que encierran sus máximas y refranes. Antecedente de la vieja Celestina es el tipo del parásito de la comedia nueva de Menandro encarnado en el personaje de Quéreas, el alcahuete o tercero, que se define a sí mismo y su modus operandi en El misántropo, como bien nota Sardón Navarro (1996: 206). Se trata de un personaje propio de la Fiesta (más tarde del Carnaval), por cuanto trata de satisfacer sus necesidades (más) primarias y ayuda o incita a los demás a hacer lo propio, coadyuvando a desintegrar el orden establecido.

La vida no es aquí un estallido de fuerza regeneradora, ni esa marea que se llevaba los pequeños afanes de los jóvenes bilbaínos; como expone Celestina y refrenda Pármeno, es lucha, es batalla primitiva en pos de las pasiones más potentes y primitivas: el placer, el sexo, el dinero y el poder de dominar las voluntades ajenas: todos ellos repartidos en diferentes personajes y reunidos en la protagonista.

Abrocha, de nuevo, Agirre el patio de butacas con el escenario y al público con los actores profesionales que encarnan papeles de la ficción, buscando lo que en una acotación se nombra como «confabulación». La obra comienza con los músicos tocando y accediendo al escenario desde el patio y Pármeno inicia su intervención sentado entre el público; algunos espectadores están sentados en el escenario y son tomados como interlocutores por los actores. Luces cenitales aíslan y dan intimidad a Celestina en determinados momentos de su evocación, mientras que en otros baja al patio de butacas como una vendedora de perfumes y ungüentos a parlotear con la gente. La ayudanta reparte vino entre el público cuando Celestina baja a vender sus ungüentos y en un momento dado algún espectador es invitado a participar de un baile y algún otro tomado como interlocutor por Celestina.

${ }^{10}$ Cuya Divina Comedia ya había sido traída a colación por la autora en María, en boca del Poeta, haciendo referencia al círculo infernal de la lluvia y el frío. 
La obra se dispone como un relato que hace Celestina al público de su propia historia, con la presunta finalidad de aleccionarlo en los peligros del desordenado amor («yo deseo hablaros de los famosos amantes, Calixto y Melibea, por cuyos amores fui muy importunada, y os lo deseo contar para aviso de los locos enamorados vencidos en su desordenado y loco amor»), aunque de inmediato anime también al «buen amor y placer de amiga», repitiendo las palabras de la Trotaconventos del de Hita. El relato de Celestina es dramatizado en ocasiones con la intervención de algunos otros integrantes del equipo, músicos que comentan o subrayan algún parlamento o idea, la Ayudanta, que imita y representa a Melibea, en un ejercicio que refuerza la intertextualidad entre el texto de Agirre y el de Rojas y la distancia entre el ahora en que se revive la historia y el tiempo pasado en el que se supone sucedida.

Se revive así la ira inicial de Melibea al serle llevada noticia del deseo de Calixto y su amansamiento por parte de Celestina, maestra en el conocimiento del alma humana y sus debilidades, lo mismo que en el arte de embaucar con la palabra y gozadora de su poder sobre las voluntades ajenas (a lo que Agirre suma el temor a perder su fama de alcahueta). Relato que se interrumpe con un pequeño episodio en el que la vieja conocedora de remedios (hasta para restaurar virgos) invoca al Diablo como valedor de sus empeños y otro (que recoge muy bien algo del vitalismo del texto de Rojas) en el que se invita a gozar de la juventud y los placeres y, en particular, del vino (del que Celestina se declaraba y declara gran aficionada), y otro de Celestina de cómo ganó la voluntad de Pármeno, criado de Calixto, evoca la figura de la madre del muchacho, prostituta y medio bruja también, que da paso a otra invitación al placer y al baile. Cuando Celestina retoma el hilo principal de su relato — urgida por Pármeno- es para presentar a Melibea ardiendo de deseo y preguntando por la causa de su desasosiego y sinvivir (y a Pármeno manoseándola mientras tanto), causa que — como es bien sabido - Celestina diagnostica como amor, con el célebre parlamento en que lo define con sus paradojas («un fuego escondido, una agradable llaga, un sabroso veneno, una dulce amargura...») y para el que propone el remedio conveniente: $\mathrm{Ca}$ lixto (a quien representará un músico), con una nueva invitación al disfrute hecha a los amantes, ahora traída por la invocación del tópico del carpe diem. El motivo siguiente es ya el de la violencia y la muerte. Pármeno acosa a los amantes presentando su relación como venal hasta que los hace huir, y acosa a Celestina para que hable del pago que recibió de Calixto por su tercería y ella cuenta cómo fue asesinada por el propio Pármeno y Sempronio por no querer repartir las ganancias con ellos, interiorizando la situa- 
ción original y dramatizando con violencia aquel momento. El relato refiere la muerte de los criados homicidas y la muerte de los amantes, primero la de Calixto al caer de la tapia del huerto donde se encontraba con Melibea, y la de ésta al arrojarse de la torre de su casa. Celestina, en una concesión vitalista, refiere haberlos visto reunidos en el Más Allá junto con otros amantes célebres. Finalizado el relato, Pármeno y un músico ofrecen al público los conocimientos de ultratumba de Celestina, quien despide a los asistentes en un ambiente de fiesta popular.

La música vuelve a ser integrante básico de la representación: músicos en escena y piezas musicales que se distribuyen a lo largo de la obra van pautando el relato y la acción, sugiriendo o subrayando estados de ánimo o contribuyendo a crear situaciones. Hay, además, tres momentos de danza que refuerzan la sensación de fiesta: uno, en el que Celestina baila acompañada de una pandereta mientras baja al patio de butacas con su cesta de hierbas y perfumes; otro, en el que es la Ayudanta-Melibea la que danza de forma muy sensual junto al público, mientras anima a la alegría: «Dancemos toda la noche, que esto calienta la sangre; te sostiene; te hace ir alegre, te refresca. Te quita la tristeza del corazón más que el oro ni el coral; da fuerza; color al descolorido, coraje al cobarde, al flojo diligencia»; el tercero se da en un momento de desfogue vitalista, tras una escena de esgrima de Celestina y la Ayudanta e implica al público, a quien se saca a bailar. La obra termina en un ambiente de fiesta popular con los actores y el público mezclados, mientras suena «Música Kalejira acompañada de cencerros, campanas, castañuelas, panderos...».

\subsection{La baladilla de San Sebastián /Chicas bonitas, alegres maizales}

La excavadora que arrasaba y se llevaba por delante el bar de Ángel en Bilbao reaparece en el final de esta obra para hacer desaparecer un mercado popular, tradicional (cuyo referente es el de la Bretxa, en Donostia) y con él la forma de vida (y de ver y hacer la vida) y las historias de muchas gentes, borradas en nombre del progreso y de los nuevos tiempos. Maite Agirre las singulariza en dos: Ixi, una vendedora que tiene un puesto de verduras, y Nordin, un emigrante magrebí (un conocido suyo, en la realidad) que ha abandonado su país en guerra y vende las alfombras, relojes o pañuelos que acarrea.

El Carnaval, con su vitalismo tiene algo de selvático, de boscoso, de sátiros y faunos, de dionisiaco y pánico que, aunque de lejos, late debajo del 
contacto con la naturaleza de las frutas y hortalizas que vende Ixi, y en sus referencias escatológicas (nunca groseras), en un escenario que tiene que sugerir que estamos al aire libre y donde pronto se establecen lazos explícitos con el público a quien los dos personajes interpelan (sobre todo Ixi que lo hace constantemente), bien sea para ofrecer su mercancía, bien para hacerlo receptor de sus ideas sobre la vida o de sus anécdotas. En un determinado momento, la acotación dispone que actores y parte del público formen un grupo que ha de ser visto como tal por el resto y se sugiere que «si no fueran muy tímidos, a lo mejor se dejarían invitar a beber un vaso de vino» (2000: 63).

La música esta vez sale del radiocasete de Nordin en forma de unas canciones árabes o del propio joven cuando canta (al final sabremos que es músico), y se carga de intensidad y dramatismo cuando refiere cómo su madre le animaba a cantar para espantar el miedo de los disparos y las bombas que sacudían su pueblo, canto que se sume en un coro y que reaparecerá en otros momentos de la obra. En otro momento, el muchacho cantará la canción de la pelea de padres e hijos, por la pérdida de las tradiciones. Ixi también evoca sus canciones y el efecto que hacían en ellas en boca de un hombre y canta alguna de ellas en escena; frente a ese tipo de canciones, la tamborrada de Sariegui, sirve para recordarle la afición de los hombres a la pelea. El acercamiento entre ambos se sustancia cuando es el joven el que tararea una canción en euskera, sorprendiendo agradablemente a Ixi, quien le aconseja no olvidar las canciones propias, las de la casa, para saber volver. Mediada la obra entra en escena el ruido de las excavadoras, pero es tapado y derrotado por el canto de un versolari que recita a Zepai; cuando vuelve el ruido, se le contrapone un sunpriñu «como una melodía árabe», el instrumento que tocaban los pastores y afiladores. Unas rumbas gitanas salen del casete de Nordin cantadas por su novia sevillana entre mucho jaleo, invitándole a volver al sur, la habanera que canta Ixi, con la que ella y su padre despidieron a la amá en su agonía (que supone uno de los momentos más emotivos de la obra). En el final de la obra volverán a oírse las excavadoras, a las que se opondrá la tamborrada hasta hacerse un silencio repentino del que brotará el hilo musical de un centro comercial y la voz grabada de una mujer que anuncia ofertas, a los que, a su vez, se opondrá el chiflo del afilador «como un aullido largo, afilado y al mismo tiempo dulzón». El final de la obra lo reserva Agirre, significativamente a un nuevo enfrentamiento, del que saldrá triunfante la vida y la alegría: sobre la voz grabada se va imponiendo la tamborrada, hasta que «En la oscuridad seguiremos escuchando la música, festiva, provocadora, desfachatadamente alegre». 
También aquí — como en otras obras — de la música se pasa a la danza. Nordin siente a su madre muerta danzando junto a él y anima a Ixi a bailar, lo que hace que la mujer recuerde sus primeros bailes y el consejo de quien les enseñaba: «como si fuera tu última danza, con el alma, no sólo con los pies». De hecho, la danza está a la base de la idea de toda la obra, con el leit motiv de que el mundo jira ta bira, va y viene, y - como dice Ixi en el parlamento que cierra la obra - «Porque de la tierra venimos y vamos y venimos y vamos y hay que trabajar y gozar en esta danza que es siempre la última, porque venimos y vamos y venimos y vamos sin parar en la danza infinita donde sólo cuentan tú, tu cansancio y tu amor propio para seguir y seguir» (2000: 90).

La obra se estructura de nuevo en dos planos: uno, el de la actualidad, en el que está sola Ixi, recordando las historias del pasado en el mercado, con Nordin, mientras vende su mercancía, y otro — evocado por ella - en el que se corporeizan algunos momentos de conversación con el joven. De nuevo la memoria y de nuevo la agilidad en el desarrollo de la historia que vuelve a conseguirse el cambio de iluminación en el que se activa lo que se indica en acotación como «la luz del joven» (2000: 31$)$.

Las fotos de Ixi, amarillentas ya, convocan a su familia: la amá y su habilidad en la costura, el aitá ruidoso; más tarde serán las anécdotas, como las del hambriento tío Hilario que, picando picando, se comió la cena de toda la familia o la de la abuela gordota que abominaba de curas y monjas, el aitona Blas que hizo mucho dinero con el contrabando y lo gastó en el juego, la abuela que parecía paralítica y se arrancó a bailar por efecto del pacharán, su novio y después marido que se fue lejos para ganar dinero, el abuelo paterno, comunista, muerto en la guerra, la abuela Rosario que quedó viuda con cinco hijos, el padre que vivió la muerte del suyo como una culpa y tuvo que trabajar desde niño, la importancia de los sastres, ya olvidados, el enfrentamiento de la abuela con la atzo zaharra, con la muerte, y la despedida en ese trance con una habanera. Historias a las que Nordin suma algunas suyas de la vida con su madre en un pueblo en guerra, con hambre, el juego de imitar animales para olvidar el hambre, el banquete que supuso un tomate cocido, el miedo y las canciones para espantarlo, la muerte de la madre.

A Ixi y Nordin les une una simpatía mutua, el cariño protector que la mujer despliega bajo una capa de rudeza que no lo consigue enmascarar y el afecto con que Nordin trata de que ella se sienta joven. Traza Ixi unas correspondencias que le ayudan a entender mejor el mundo y la situación del muchacho, en quien se ve tiempo atrás: la guerra de la que éste huye y la vio- 
lencia de la ciudad, el hambre de Nordin y la que pasó la familia de Ixi tras la guerra y el hecho de que ambos sean, a su modo, elementos ajenos en un mundo que va cambiando muy de prisa y acerando sus aristas: ella, en la cincuentena (ya no es «gacela joven, sino perro viejo»), esa incómoda edad para quien ve que se extingue su mundo y su forma de vida («ahora que se me han acabado los sueños se me va acabando el resplandor», 2000: 53); él, un extranjero, un emigrante, un cuerpo sentido como ajeno en el tejido social y económico. En su vitalismo, Ixi ve en África la pervivencia de un contacto natural del hombre con la tierra, perdido en Occidente, y ve en Nordin la juventud ida y con ella la valentía ante el riesgo (como la tuvo el propio aitona Blas), el deseo de los cuerpos, las romerías y los bailes y los versos picantes de los bertxolaris, los olores y sabores antiguos; para ella los jóvenes occidentales de hoy han perdido esa vitalidad e incluso se vuelven sombríos de forma prematura. «Trabajar duro y gozar mucho del baile» «y comer bien y sano», resume para Ixi su vida en la juventud (2000: 27); «chicas bonitas y alegres maizales» (2000: 25), evoca para él lo mejor de su pueblo. La picardía y el descaro de la mujer al hablar de cuerpos y deseo, es correspondida con desenvoltura fresca por el muchacho («En mi pueblo se dice: Si no bailar, no saber amar, no hacer bien el amor»). Nordin siente en la mujer alguien que lo aprecia, lo comprende y acepta tal como es (aunque parezca regañarle a veces), y llega a recordarle a su madre muerta; coincide con la mujer en valores sustanciales como el respeto y el cariño a sus mayores y el aprecio por las cosas sencillas, el disgusto por la prisa del mundo moderno: «Vayamos por la vida lentamente. Con más apego a la tierra y al momento», cita Ixi a María Lejárraga (2000: 78) ${ }^{11}$.

\subsection{Cabaret infantil (Haur Kabareta)}

Cabaret infantil es una propuesta de teatro para niños (y adultos con espíritu lúdico), divertida, imaginativa, creativa y, por supuesto, participativa, en cuya autoría colaboran Maite Agirre, Santiago Ortega e Inés M. de Iturrate. En la página del documento que presenta el espectáculo los autores indican que se trata de «una historia sobre la amistad y la necesidad de quererse a

\footnotetext{
${ }^{11} \mathrm{Me}$ indica la autora que «la puesta en escena definitiva tuvo dos versiones: Una primera con el acompañamiento en directo de un grupo rock-funki, Freenetic, que hacía las veces del grupo de músicos al que pertenecía Nordin. Su presencia aparecía y desaparecía ya que se encontraban tras una malla negra y según desde donde se les iluminaban se podía mostrarlos u ocultarlos por completo. Seguidamente se realizó una segunda versión con un acompañamiento de músicos africanos de folk llamados JUM-JUM, que jugaban el mismo rol».
} 
uno mismo», aunque creo que está más claro lo que dicen a continuación, que las dos chiquillas protagonistas «proponen la música como un juego para compartir con los demás sus fantasías e inquietudes».

Este cabaret tiene un doble marco: el cuento que Paki —una de las protagonistas - está leyendo, dentro del cual está su amiga Mari, en una duermevela perezosa antes de ir al colegio, en la que tiene una ensoñación a la que llegan las voces de su madre que la llama y le manda recoger. Voces que terminarán despertandola, momento en que terminará el cuento, para dar lugar a la reunión final de actores y niños del público.

Amparada por la ensoñación, la fantasía hará que un títere cobre vida, lo mismo que una gran caja para recoger los trastos desperdigados por la habitación o que de ella surja un joven músico cuentacuentos, o que aparezca el cantante famoso de un póster de las niñas.

La música entra pronto para propiciar el juego: Mari trata de hacer dormir a un pequeño títere (su hermano) que acaba de tirarla de la cama, tocando el chelo, lo que anima a Paki (más dada al fútbol) a pedirle que le enseñe, y fantasee con la posibilidad de hacer una orquesta. El joven cuentacuentos relata y canta la «Balada de la luna y la doncella», comenzando una serie de propuestas humorísticas y divertidas (aquí la niña se hace mayor y hace turno de noche en Pizza moon). La pizza de verduras enciende la bombillita imaginativa de Paki que se entusiasma con la idea de hacer música con verduras, música «pepinofónica», situación en la que los niños del público ya serán llamados a participar. Terminada la Jam sesion, Paki se sincera con el público hablándole de cómo se va haciendo mayor, lo que da lugar a la canción «iQué bien, ya soy mayor!» (una de cuyas estrofas dice: «Ya sé cuánto son dos y dos./ Ya sé atarme todos los cordones/ y puedo comer dos platos de macarrones./ Por la noche nunca tengo miedo/ y a mi peluche yo lo defiendo.»). Ido el joven cuentacuentos ( $¡$ al que le suena el móvil en escena para regocijo del público!), las chiquillas hablan de sus cosas y, por supuesto, de chicos y, más en particular, de lo que es fashion, lo que da lugar al «Rap de Paki», compuesto por Mari, que enlaza con la «Canción de Sergio», un cantante de moda que aparecerá en todo su esplendor de super-star, en un concierto en el que está cantando: «Y yo que fui con Marisa al Café Internet/ La miré a los ojos y juntos navegamos por la red/ Comemos un gofre y luego andamos a pie/ —No sé, yo prefiero el autobús.»; pero su gran éxito no es éste, sino «Tomate song», más directo y contundente: «Cuando voy caminando por el campo/ yo me pongo muy contento si me encuentro.../ jun pimiento!/ y cuando digo pimiento quiero un.../ ¡pimiento!»; canción que 
anima al público a participar en una nueva coreografía, con sombreros amarillos y tuttifruti. El bis que regala el cantante a Paki ensalza el fútbol, pero Mari prefiere la pala (que también tendrá su canción), con un baile del juego de pelota. Tras este clímax musical, la historia se calma y da paso a una pequeña escena de títeres y recortables en la que las dos niñas recorren el mundo en globo con una orquesta pepinofónica formada por niños de diferentes razas. La voz de la madre saca a Mari del ensueño, pero no de la idea que la entusiasma de formar esa orquesta.

La propuesta de Cabaret busca ofrecer estímulos variados y sumados a los niños del público. Es por esto por lo que algunas acciones suelen estar complementadas por otras. Así sucede en la escena de la «Balada de la luna y la doncella», en la que, mientras el cuentacuentos canta, Mari va recreando la historia con su almohada, o en la de «iQué bien, ya soy mayor!», que va acompañada «de los saltos y acrobacias del joven, la dirección cómica de Paki y el acordeón de Mari, que toca entre los niños del patio de butacas a los que les deja probar a tocar algunos botones del instrumento.» Cuando Mari canta la «Canción de Sergio», lo hace poniéndose una chistera amarilla y unos tacones dorados desde los que se cae.

\subsection{Ramón y Ramona/ Secando charcos}

En Ramón y Ramona Maite Agirre explora otro tipo de teatro, de formato más «tradicional», cerrando la «cuarta pared» y abandonando la metateatralidad y la participación festiva del público, a quien se ofrece, en cambio, asistir como observador (sin otros estímulos que lo distraigan), a un enfrentamiento entre un hombre y una mujer tenso, denso, doloroso y electrizante, que puede traer el recuerdo de obras como Casa de muñecas, de Ibsen, o Carta de amor (Como un suplicio chino), de Arrabal, textos narrativos como Revolucionary Road, de Richard Yates o La escala de los mapas, de Belén Gopegui, o - como indica la propia autora— una película como Secretos de un matrimonio, de Bergman.

Agirre especificó el sentido de su obra, describiéndola como «Una pareja de hoy en día, un hombre y una mujer que miran sus vidas desde su juventud hasta su madurez, preguntándose sobre el amor, sus sueños, lo que cada uno es..., lo que esperaba cada uno para su vida personal, también para su vida juntos, desde el compromiso, la apuesta por hacer realidad tu vida, el amor por aquel sueño de juventud, etc.» («El gran milagro del teatro», 2010). En la acotación donde se indica la acción de Ramona modelando el 
cuerpo de Ramón y su sentido, la autora habla de «la relación ambigua y dolorosa de Ramón y Ramona», también de que la suya es «la historia de un hombre y una mujer, una historia que habla de su ternura, su insensatez, su grandeza, su mediocridad, su generosidad, su soledad, su búsqueda...».

La obra está estructurada como un flash-back, que presenta el recuerdo de Ramona, a punto de irse, de lo que acaba de suceder en su cena de despedida «romántica» con Ramón, su pareja durante 16 años. Sobre este recuerdo - presentado de forma realista - se abren momentos de cierta irrealidad para mostrar el interior de Ramona y Ramón (con monólogos líricos que recuerdan a Virginia Woolf) e, incluso, anticipaciones del viaje en avión en que la mujer se irá lejos y la carta que habrá dejado para Ramón.

Se trata de una cena íntima que ambos proponen hacer «mágica», hermosa, única, inolvidable, desinhibiéndose y recuperando una alegría festiva hecha de abundancia de sexo, comida, bebida, risas, gritos, llantos, falta de normas y ataduras, y donde tenga cabida un egoísmo hedonista. Una especie de compensación por la pérdida y la represión, la «reducción» que ha ido suponiendo para ambos su relación. Pero esa propuesta incluye también, o no quiere evitar, hablar de ellos mismos, analizar el fracaso de su relación, reprochar al otro sus defectos y defenderse de sus reproches, y plantear un futuro separados, desde el dolor y la nostalgia por la pérdida y unos celos prospectivos.

La situación de partida y la relación de fuerzas entre ambos personajes va cambiando a lo largo de la noche: de un cierto equilibrio en el comienzo, donde intentan colaborar para construir su noche mágica (al tiempo que parecen tentar el terreno para la esgrima y se les escapan los primeros arañazos), se pasa al desequilibrio producido por el anuncio de Ramona de su embarazo, que descoloca y exaspera a Ramón y lo pone en una defensiva agresiva; es el momento de los reproches mutuos, también de las confesiones íntimas (el miedo a ser abandonado, el miedo a ser herida) y del erotismo como último asidero, que parece sosegar de nuevo la situación: un momento de erotismo, cargado al principio de ansiedad y lastrado por el fracaso, que termina siendo festivo, de caricias y juego, de desnudo físico que ambos pretenden sea también emocional. Pero la incapacidad de Ramón para aceptar la maternidad de Ramona o, más bien, que ese hijo no sea suyo ( «Un hijo que no es mío es para matarte») realimenta la tensión y los reproches hasta que, ya calmados, se despiden entre insultos más o menos cariñosos, quedando Ramón abatido.

La obra descansa en el diálogo y fía en él su efecto. Se trata, por tanto, de un intercambio verbal significativo y eficaz que lleva en sí el contenido de la 
obra, de las dos miradas sobre el mundo y sobre la relación de pareja y que debe recargarse y relanzarse constantemente para mantener una intensidad que ya es alta desde el comienzo. Todo contribuye en él al enfrentamiento y a la tensión, con la peculiaridad de que, a pesar de la ruptura, sigue habiendo cariño y pena y rabia por haber llegado a ese final; a los dos les duele el fracaso y la derrota y la culpa del otro y la responsabilidad propia. Lo monotemático del diálogo, centrado en los asuntos sentimentales, parece atenuarse en algún momento con la entrada de otros «motivos», sobre todo con los propios de la situación de cocinar y comer (la sal, el engordar o no, la celulitis, las cremas de belleza como máscaras...), aunque pronto se conducen también al cauce principal, como munición para el combate. Y lo mismo ocurre con algunas quiebras en el diálogo que parecen servir para cambiarlo de dirección o hacerle perder una intensidad dolorosa, cuando en realidad sirven para intensificarlo y descolocar al interlocutor (como cuando Ramona, después de anunciar que está embarazada, dice de inmediato que los chipirones se están enfriando).

Lo que se dicen Ramón y Ramona mientras cocinan y comen y tratan de amarse, va poniendo de manifiesto la forma de ser de cada uno de los dos, las expectativas que tuvieron, y su decepción por el fracaso de la relación. Ambos parecen haber tenido la lucidez suficiente para mirarse en el espejo y reconocer su nueva condición: Ramona — que es quien lleva la iniciativa de la ruptura- ha visto en él a una nueva mujer que necesita dejar atrás esta etapa de su vida, donde sus expectativas de tener «una vida intensa» y no traicionarse nunca están fracasadas en una relación que, si ha sido hermosa, ya está agotada («vaciada») y les causa dolor. Ramón, descolocado, dice también haber descubierto a un hombre libre, pero no hay convicción en su discurso y el desarrollo de los acontecimientos en la noche lo irá mostrando confuso y desbordado.

El diagnóstico que hacen del fracaso indica que han sido incapaces de conservar su amor porque no se han aceptado tal como eran y se han ido encerrando en sí mismos, desde el orgullo, perdiendo ilusión y contacto. Abundan los reproches mutuos a lo largo de esta cena catártica, lanzados tanto desde la calma como desde la tensión y la exasperación. Ramón le reprocha a la mujer una cierta tendencia a encerrarse en sí misma y a controlarse en exceso (después de un momento inicial de vitalidad desbordante), además de ser orgullosa y su peor enemiga. Ramona reprocha a su pareja justamente lo mismo: orgullo y encerramiento en sí mismo, además de una tendencia (que tilda de masculina) de controlar a la mujer, o sus otras amantes o dar excesiva importancia al éxito en el trabajo entendido de for- 
ma competitiva y ligado a un estímulo sexual. Pero también hay aceptación de las culpas propias, sobre todo por parte de Ramón, que termina reconociendo haberse sentido descolocado y desbordado, anonadado por la entrega inicial desinhibida y total de Ramona, incapaz para quererla de ese modo, incapaz, siquiera, de aceptarla así, sin reservas, dado que él no estaba en disposición de corresponder de la misma manera. Algo que, en el repliegue y la reserva, conllevó el desconocimiento de cómo es, realmente, el otro, lo que los desasosiega especialmente esa noche: no haber sabido, querido o podido acceder al fondo verdadero de su pareja y también el miedo de quedar ahora al descubierto, sin defensas ante el otro y aflore algo de ira y de rencor: los de Ramón por el embarazo de Ramona, los de ésta por la incomprensión machista de aquél. La mirada hacia el futuro hace aparecer en la conversación algunas expectativas, algo enturbiadas por lo complejo de la situación. Ramona se plantea tener una nueva vida «diferente, distinta, mejor», decidida, además, únicamente por ella, amar, escribir y no suicidarse y (aunque disuene) no soñar. Ramón —que va a remolque en casi todo en esta despedida, ya que no la acepta- dice que desea desprenderse de todo lo que le ha estorbado y le ha maniatado, aunque no sea capaz de especificarlo.

La escenografía de esta obra es sencilla (cocina americana con saloncito), pero no es fija: «aparece y desaparece»; el suelo se convierte en un espejo que refleja a los actores, en un intento de potenciar un motivo básico de la obra: la indagación sobre la identidad de los personajes. La música se reduce en este caso a una canción que suena en la radio y que mueve a Ramona a bailar y, sobre todo, a un vals que funciona como un indicador en la acción y suena en el comienzo y en el centro de la obra, momentos en los que Ramón y Ramona bailan de forma cómica (ella risueña, él patoso y tragicómico), buscándose y encontrándose en sus cuerpos ${ }^{12}$.

\subsection{Las versiones «quijotescas»}

Después de la Celestina es El Quijote el gran mito que viene a encontrarse con Agirre y su grupo, físicamente, incluso — se podría decir-, ya que

${ }^{12}$ La puesta en escena definitiva — tal como me informa la autora- se realizó con dos actrices y dos actores siendo Ramón y Ramona jóvenes y Ramón y Ramona adultos, mirando así su pasado desde las experiencias de la juventud (como en Bilbao. Lauaxeta, tiros y besos). La música finalmente también se realizó en directo con la actriz Inés Martínez de Iturrate que la compuso y la tocó en directo con instrumentos como el chelo o el acordeón. 
la idea de trabajar a partir del texto cervantino les sobreviene en Argamasilla de Alba, llevando su iPuta, vieja, alcahueta, Celestina! ${ }^{13}$.

La condición dinámica del teatro de Agirre y Agerre Teatroa se constata muy bien en las diferentes versiones del Quijote elaboradas con una materia común (proveniente, en sustancia, del texto cervantino) que va tomando diferentes formas y adaptándose a diferentes lugares (Maputo, Gallarta...) y diferentes públicos (adultos, niños).

\subsubsection{Dulcinea y el Caballero de los Leones}

La versión «madre» — por así decir- es la titulada Dulcinea y el Caballero de los Leones, cuyo andamiaje o hilo principal de la trama es sencillo: un grupo de gentes del teatro (actores, músicos, técnicos), algo alocados, quieren contar y representar el Quijote, para lo que solicitan la participación del público y su complicidad. Literatura dentro de la literatura, teatro dentro del teatro, teatro llevado a la fiesta, en este caso con una propuesta construida alrededor de «un libro que enseña a soñar» (como se dice de El Quijote en un momento determinado de esta obra) y de la «figura del soñador» (como dice Agirre en una entrevista hecha por Kutsenba Carta o, en relación con la puesta en escena de esta obra en Maputo), propuesta en la que público y actores podían vivir la «aventura de soñar» y reírse «del loco soñador, enloqueciendo y soñando todos, porque un mundo distinto siempre es posible, a medida de la persona, superando día a día nuestros límites y atreviéndonos a soñar todos los días.» («El gran milagro del teatro», 2010). Y junto al soñador, su sueño, su ideal: Dulcinea.

En un momento de la obra, Doltza pregunta a Sancho si Dulcinea existe o es una creación de la imaginación, y en otro, el Titiritero-Mago lo preguntará a varios espectadores. También en Kutsenba Cartão, la autora explica su forma de entender a Dulcinea: «Dulcinea es algo precioso. Yo me pregunto si existe, o si somos cada uno de nosotros buscándonos a nosotros mismos... Dulcinea es algo inagotable, es El Dorado de Agirre, o tal vez no, tal vez es mi vecina de al lado. Cervantes en un momento dado la presenta oliendo fuertemente a ajos. Esta anécdota la trabajamos en Maputo y ese momento entre el público buscando a Dulcinea resultaba apoteósico. Fue una gran di-

${ }^{13}$ De un espectáculo a otro son varios los componentes que pasan, y Maite Agirre hace referencia explícita a su parentesco en una de las notas de su texto-guión: «Como veréis las alusiones a Celestina son constantes, pero no me importa, ya que desde el principio he tenido claro que Alonso Quijano es un hijo de Celestina y como tal sabrá individuarse, aunque empiece mamando de su leche». 
ficultad sustituir el olor a ajos de una mujer por otro olor con significados y sugerencias parecidas... hubo debates, discusiones... Teníamos que elegir a alguien entre los espectadores, una mujer, y decir que olía a ..., y ese olor la hacía real, carnal, de verdad, sin ser ninguna ofensa para ella, porque en un momento dado Ducinea dice: «Las mujeres queremos ser reales», algo como “queremos existir"» («El gran milagro del teatro», 2010).

Imbuida de estas ideas, la autora pone en boca de sus personajes propuestas concretas de valores y formas de vida. Así, el Titiritero-Mago habla del «caballero que todos llevamos dentro», o afirma: «Felicidad a los que apuestan fuerte en el amor, sólo amando se es libre». Sancho, por su parte, dirá que «al igual que el caballero D. Quijote todos deseamos abrirnos al mundo y a sus aventuras, pero cada vez tenemos más y más miedo y terminamos encerrados en casa [...] Es así como nos vencen. Con mucha tele y poco contacto con la vida, olvidando los juegos, las aventuras, olvidando escuchar los relatos que nos cuentan». Hay en la obra una clara llamada a no perder la ingenuidad del niño ni su capacidad lúdica, ni la ilusión por la aventura y, correspondencia, un rechazo de los barberos y curas, recortadores de barbas y de ideas, fantasías y sentimientos.

El Quijote, a la luz de este Caballero de los Leones y de otros textos posteriores, se ve como un texto clásico muy motivador para la creatividad de la autora, en relación con el que se activan algunas de las ideas de Maite Agirre y de Agerre Teatroa sobre la forma de ver y hacer el teatro y de ver y hacer la vida. Manejo - por generosidad de la autora - un texto de trabajo de la compañía («en preparación» ${ }^{14}$ ) que permite comprobar con más nitidez alguno de sus rasgos y de los rasgos de todo el teatro de esta creadora. Ya en el dramatis personae Agirre explica que en el personaje de Teresa Panza hay rasgos de Dulcinea, por lo que prefiere llamarla «Doltza». El Titiritero 2 y el Chamán son encarnados por varios actores y el segundo comporta la utilización de máscaras ${ }^{15}$ rituales, ya que supone «las caras cambiantes de nuestros ancestros», mientras que el primero viene a representar la actualidad, también cambiante, pero sin pasado, «o sea, comedia del arte». En cuanto a los espectadores, se incluyen expresamente como participantes y la consideración de Agirre es muy clara al respecto: «Los que haremos sentar en el mismo escenario. Estos interactuarán a lo largo de la obra. En Agerre teatro ya tenemos experiencia de ello en diferentes

${ }^{14}$ En un momento determinado del texto-guión, la autora dice: «Se probarán posibilidades que en el transcurso de los ensayos irán saliendo».

${ }^{15}$ Con las máscaras ya había trabajado la compañía en Pantzart, con estudios plásticos del pintor Vicente Ameztoy para las máscaras de los diferentes personajes de la pastoral carnavalesca. 
espectáculos y sabemos que se crean situaciones muy hermosas» ${ }^{16}$. Y así se hace en diferentes momentos, de manera motivada, incardinando las propuestas con motivos o momentos de la trama, animando a algún espectador, por ejemplo a que cuente una pequeña historia de sus afectos como don Quijote escribió una carta de amor a Dulcinea o convertirá a una espectadora en Dulcinea o repartirá títeres entre los espectadores para crear un ambiente guiñolesco, o lo invitará a comer y a beber o a agitar paños o aspas de molino.

La obra está armada sobre el bastidor que supone el retablo de Maese Pérez y el relato (como en La Celestina) que hace de varios pasajes del Quijote, con algunos comentarios sobre su sentido, contrapunteados en varias ocasiones por las intervenciones del Chamán que coadyuvan a radicarla en África. Sobre este bastidor resaltan las figuras de Sancho y Doltza, que conversan sobre los episodios del Quijote o sobre sus personajes, en un juego intertextual, pero también sobre sí mismos y su estrecha y cariñosa relación, en un añadido interesante de Agirre al texto cervantino. Si Teresa - como he dicho- tiene mezcla de Dulcinea, Sancho está visto, desde el final de su experiencia al lado de don Quijote, como un personaje transformado por los sueños de su señor y, por tanto, ennoblecido, en el que también queda su vitalismo, su ingenuidad infantil y su apego a las cosas cercanas, que Dolzta no quiere que se pierdan y con las que lo embroma cariñosamente (comida, pedorreo...).

La obra se estructura en escenas breves puntuadas con música o algún efecto (de agua, por ejemplo). De nuevo se ve que el espectáculo es concebido de forma participativa, dinámica y global, yendo, en este último sentido, más allá del texto con elementos visuales y auditivos, con la intervención de componentes como la música, la multiplicación de actores para un personaje, la utilización de títeres, la transformación de títeres en personas o la utilización del actor como si fuera un títere ${ }^{17}$, escenas muy plásticas (como la de la agresión de los presos a don Quijote ${ }^{18}$ o la de la quema de li-

\footnotetext{
16 «No vamos a olvidar que será un espectáculo en el que el espectador ha de sentir que la obra de teatro la hace también él», recuerda la autora a su equipo en un momento del texto-guión.

${ }^{17}$ Aunque la utilización de títeres — como me informa la autora— se haya reservado a la versión infantil, para aligerar así los otros espectáculos.

${ }^{18}$ Para la que la acotación dispone o, mejor, propone: «Aquí el tema musical sube de intensidad sea con txelo, el trombón de Kepa, la txalaparta... D. Quijote con su lanza, que es una rama de un árbol, realizará su danza guerrera. Se suman instrumentos musicales y poco a poco los diferentes elementos repartidos entre el público que está en el escenario. Se puede atacar a D. Quijote con ramas, que harán mucho volumen y ruido». Y lo mismo puede decirse de las rejas que pueden llevar algunos espectadores o de otros elementos que buscan «un minimalismo plástico de gran fuerza visual» (teniendo como referente a Kantor), de la utilización de ruidos duros mediante el entrechocar de piedras, para sugerir la lapidación del caballero, a quien puede vestirse con un sari para homenajear a las mujeres y oprimidos maltratados, o el convertir el cuerpo en una txalaparta sobre el que percutir.
} 
bros $^{19} \mathrm{o}$ la aventura de los molinos ${ }^{20} \mathrm{o}$ la del caballo Clavileño ${ }^{21}$, la de la batalla de don Quijote con monstruos y gigantes ${ }^{22}$, la de don Quijote enjaula$\mathrm{do}^{23}$ ), logrando un atractivo espesor significativo y unas propuestas sugerentes. En todo caso, han de ser «Ideas sencillas y plásticamente tan expresivas como realizables. Nada de cosas complejas o maquinarias imposibles». En determinados momentos, la introducción de anacronismos pone una nota humorística en el espectáculo y «actualiza» el Quijote: las mochilas y las tiendas de campaña que llevan D. Quijote y Sancho, las referencias a los sindicatos, cuando hablan del sueldo de Sancho, a los e-mails que propone Ginés enviar a Dulcinea, en vez de ir a verla, la televisión con la que se nos atonta

Los pasajes del Quijote relatados, representados y glosados en esta obra son el del enfrentamiento de D. Quijote con el león enjaulado (que relata Sancho y mueve al enfado de los títeres del ama y la sobrina del caballero), el de la carta de don Quijote a Dulcinea, el de la liberación de la cuerda de presos de la Santa Hermandad, el del expurgo y quema de libros (que Agirre aprovecha para homenajear la vida y la libertad que encierran), la aventura de los molinos, el discurso paródico de la Edad de Oro (que se dramatiza brevemente de forma jocosa), la conversación de Don Quijote y Sancho sobre la fama alcanzada por la primera parte de su historia, y otra sobre el altísimo valor de la libertad, escena que se completa con la de Marcela, la de la burla hecha a don Quijote en el palacio de los Duques sobre el encantamiento de Dulcinea y el remedio consistente en que Sancho se azote, la aventura del caballo Clavileño, la de Dorotea y el engaño a que se presta para volver al caballero a su casa y el encuentro y derrota con el Caballero de la Blanca Luna.

\subsubsection{Doltza, Dulcinea Quijote versus Teresa Panza}

A la vuelta de Maputo, Agirre reescribe Dulcinea y el Caballero de los Leones en una versión que titula Doltza, Dulcinea Quijote versus Teresa Panza, obra en la que permanecen la mayor parte de los componentes de la

${ }^{19}$ Para la que se propone un círculo de velas a cuyo interior se arroja hojarasca o tierra para sugerir y simbolizar como la ceniza de los libros quemados es semilla de nuevas historias.

${ }^{20}$ Pensada de forma plástica y participativa repartiendo lienzos o aspas entre el público.

${ }^{21}$ En la que se sugiere las chispas de un soldador como humo cambiante de color, con música de txalaparta y danza.

${ }^{22}$ Vista desde la plasticidad del carnaval o de alguna fiesta popular: «Tal vez alguna alusión a algún carnaval rural, al igual que en PANTZART inspirado en el carnaval de Lanz.»

${ }^{23}$ Donde la jaula se compone con las txalapartas. 
primera, donde se suprimen otros (el Chaman y sus parlamentos, y las referencias africanas son lo más señalado) y se añaden componentes nuevos. Llama la atención el fuerte subrayado de metateatralidad que se aplica a la función, con constantes referencias a qué hacer y cómo y muchas discusiones entre los actores que terminan la obra fuera del teatro. Muy destacable es también el hincapié hecho en la idea de trazar un camino que permita volver a casa, ya que la meta de casi todos (no de Sancho) parece ser esa, junto a la de que el caballero recobre la razón y a su familia. A ello se suma la idea de hacer de Dulcinea algo real y las tentativas para encontrar en quién encarnarla. La figura de don Quijote, interpretada por un tenor (la música vuelve a ser capital), tiene mayor presencia física en esta versión y gana en peso dramático con intervenciones más frecuentes y relevantes (destrozar el camino de vuelta a casa, preguntarse por qué huye de Dulcinea, enfrentarse a Teresa...). No pierde aquí Agirre el contacto con otras tierras y la idea de interculturalidad e incluye en el reparto a Mohamed, un vendedor de agua que añora a su familia, al que se suma John el Músico, un actor-músico norteamericano de Missouri, a quien, humorísticamente, se quiere hacer pasar por Dulcinea.

Desde el punto de vista escenográfico un cambio muy llamativo es el protagonismo dado a una gran txalaparta colocada en el escenario que, además de su finalidad musical, servirá como cama o para ceder piezas para hacer una casa o un camino ${ }^{24}$.

\subsection{3. ¿Es usted también don Quijote?}

¿Es usted también don Quijote? es una versión de la anterior en la que se reacomodan de nuevo algunos componentes, como el refrenar algo la metateatralidad (con lo que la obra gana en agilidad y concentración dramática), el dar más peso a la condición de ciclista de D. Quijote, la presencia de artistas plásticos que «crean» a Dulcinea en el escenario con sus obras o montajes, o la plasmación de Dulcinea encantada en una joven que cruza desnuda el escenario. Llevada la obra a Gallarta, «entrañada» en ese lugar, se activan referencias locales como las que se hacen a «paisajes mineros y re-

${ }^{24}$ Como versión, la encuentro menos redonda y potente que Dulcinea y el Caballero de los Leones. El texto de ésta última está más «limpio», es más nítido y la transición entre los diferentes motivos y entre las escenas está más motivada y es más suave. La figura del Chamán, además, da otra dimensión más trascendente y profunda (además de sugerente) a la obra. 
volucionarios», a Dolores Ibárruri o a canciones populares célebres como la «del tapón del garrafón».

\subsection{4. ¿Quién ha visto a Dulcinea?}

¿Quién ha visto a Dulcinea?, «versión familiar», más orientada a los niños, subraya la idea de buscar la casa de Dulcinea (y con ella los sueños, la ilusión, el amor) y potencia los estímulos del juego y la fiesta en la que participan los pequeños (con alguna escatología divertida como un pedo grande para despistar a don Quijote). En esta versión, Doltza y Teresa son dos personajes distintos y son grandes amigas, aparece el títere infantil Pomelo (al que no le gusta leer), don Quijote duda de la identidad y bondad de los niños del público y amenaza con atacarlos, la cárcel de los galeotes es «el rincón de pensar», se ve cómo crecemos con nuestros sueños y cómo don Quijote y cómo don Quijote descubre al final el niño que fue. El niño que de mayores debemos conservar dentro de nosotros.

\section{REFERENCIAS BIBLIOGRÁFICAS}

BAJTÍN, M. (1987). La cultura popular en la Edad Media y en el Renacimiento. El contexto de François Rabelais. Madrid: Alianza.

CARO BAROJA, J. (1985). Disquisiciones antropológicas. Madrid: Istmo.

- y TEMPRANO, E. (1985). «Las fiestas populares también se marchitan», En Disquisiciones antropológicas, J. Caro Baroja, 293-301. Madrid: Istmo.

AGIRRE, M. (2000). La baladilla de San Sebastián. Hondarribia: BreveSkene.

- (2002). Y María, tres veces amapola, María... BILBAO. Lauaxeta, tiros y besos. Elorrio: Artezblai.

- (2010). Doltza, Dulcinea Quijote versus Teresa Panza. Maputo: Kutsemba Carta o.

- (2011a). Puta vieja alcahueta celestina! o Los amores tragicómicos de Calixto y Melibea. Texto inédito.

- (2011b). Cabaret infantil. Texto inédito. 
- (2011c). Dulcinea y El Caballero de los Leones. Texto inédito.

- (2011d). ¿Es usted también don Quijote? Texto inédito.

- (2011e). ¿Quién ha visto a Dulcinea? Texto inédito.

- (2011f). Ramón y Ramona. Texto inédito.

GARCÍA PASCUAL, R. (2006). Formas e imágenes grotescas en el teatro español contemporáneo. Madrid: Fundación Universitaria Española.

LEONARD, C. y GABRIELLE, J. P. (eds.) (2008). Teatro español del siglo XXI. Actos de memoria. Winston-Salem, NC: Editorial Teatro.

NIEVA DE LA PAZ, P. (1999). «Y María tres veces amapola María (1998), de Maite Agirre: una visión del testimonio histórico y existencial de María de la O Lejárraga (1874-1974)». En Teatro histórico (1975-1998) Textos y representaciones, J. Romera Castillo y F. Gutiérrez Carbajo (eds.), 399-408. Madrid: Visor Libros.

SARDÓN NAVARRO, S. (1996). «Formas del Carnaval en el Teatro. Del "realismo grotesco" de Aristófanes, a los "criados" de la comedia de Menandro». Castilla 21, 195-212.

«Maite Agirre», en aee. Auñamendi Eusko Entziklopedia http://www.euskomedia.org/aunamendi/21056).

«Y del frontón de pelota nos vamos de hoz y coz al teatro popular: Pantzart», en http://www.facebook.com/note.php?note_id=360932550855.

««El gran milagro del teatro»... Entrevista con la dramaturga, actriz y directora artística Maite Agirre», en Kutsemba Cartão «Uma página aberta ao porvir», 11-7-2010, en http://kutsemba.wordpress.com/.

«Secando charcos. Una obra sobre el amor» http://www.euskalnet.net/ agerreteatroa/webpage/obras/charcos/galeria/secando_charcos.pdf. 
